\title{
Evaluation of Modulatory Effect of Combination of Spondias Pinnata and Whey Preparation on Intestinal Antioxidants and Inflammatory Markers in Etoposide Induced Rat Model for Mucositis
}

\author{
Vyshnavi, Gayathri Rao*, Shyamala Nayak, Beena Shetty
}

\section{Vyshnavi, Gayathri Rao*, Shyamala Nayak, Beena Shetty}

Department of Biochemistry, Kasturba Medical College, Manipal Academy of Higher Education, Mangaluru, Karnataka, INDIA.

\section{Correspondence}

\section{Dr. Gayathri M Rao}

Associateprofessor in Biochemistry, Kasturba Medical College, Centre for Basic Sciences, Bejai, Mangaluru 575004, Karnataka, INDIA.

Phone no : 9448951498

E-mail: gayathri.rao@manipal.edu

\section{History}

- Submission Date: 11-12-2017;

- Review completed: 14-02-2018;

- Accepted Date: 05-04-2018

\section{DOI : 10.5530/pj.2018.4.105}

Article Available online

http://www.phcogj.com/v10/i4

\section{Copyright}

(c) 2018 Phcog.Net. This is an openaccess article distributed under the terms of the Creative Commons Attribution 4.0 International license.

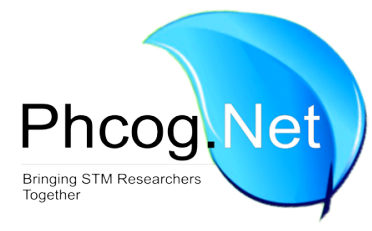

\begin{abstract}
Background: Etoposide is an important chemotherapeutic agent that is used to treat a wide spectrum of human cancers. The efficacy of this drug is often limited due to severe sideeffects such as mucositis, anorexia, myelosupperssion, alopecia. At present there are no anti-mucositic agents without side effects. To combat these side effects of cancer treatment, innovative and specific nutritional interventions are needed. The experimental procedure included an oral treatment with combination of Spondias pinnata and whey preparation (100 mg/kg b.w).on etoposide induced mucositis. Methods: Study was conducted at Central Research Laboratory, Kasturba Medical College. Rats were sacrificed by cervical dislocation and duodenum collected for estimation of biochemical parameters. Estimation was carried out for assessing the levels of TAO, GSH, LPO, NO and activity of MPO. Correlation analysis was performed by one-way Anova using graph pad prism to find the relation between control and test. Result: The antioxidant (TAO and GSH) were found to be significantly high in the rats which received the combination compared to the individual Spondias pinnata and whey treated groups. Administration Spondias pinnata and whey in combination shows significant decrease in the TBARS, NO and MPO levels. Conclusion: Spondias pinnata and whey preparation supplementation in combination have shown mucoprotective effects in rat model. Hence it can be considered as anti-mucositis therapeutic agents which can be safely administered during chemotherapy and can reverse mucositis.

Key words: Etoposide, Mucositis, Myeloperoxidase (MPO), Lipid peroxidation (LPO), Nitric
\end{abstract} Oxide (NO), Spondias pinnata, Whey preparation.

\section{INTRODUCTION}

Chemotherapy and radiotherapy are mainstay regimens for cancer treatments. However, both types of cancer treatment also affect normal cells, and their side effects on highly proliferative tissues have significant problems. One of these adverse effects is mucositis, a painful inflammation and ulceration of the mucous membrane lining the gastrointestinal tract (GIT). Mucositis can affect the entire mucosal lining of the GIT, but the oral and oropharyngeal mucosa are common sites.

Mucositis, the mucosal barrier injury, is one of the most devitalizing side effects of radiotherapy and chemotherapy treatment. ${ }^{1}$ It is characterized by both inflammation and cell loss in the epithelial barrier lining, especially the gastrointestinal tract., ${ }^{2,3}$ The side effects of chemotherapy can be traced to cause myelosuppression, alopecia and mucositis. ${ }^{4}$ Chemotherapy causing inflammation and ulceration of mucous membrane lining the digestive tract, which results in reduced food intake and drop in the $\mathrm{pH}$ levels and may cause treatment reduction or withdrawal..$^{5}$ Intestine being an important organ required for absorption of nutrients, due to the side effects the patients likely to suffer from loss of appetite and may also have deficiencies of vitamins, minerals etc. Thus, innovative and integrated nutritional approaches are needed to target several of these altered processes. ${ }^{6-8}$ Extensive experimental outcomes reported that many of the agents including growth factors like palifermin, NSAID, sucralfate, antifungal medicines etc. Drugs currently under investigation include keratinocyte growth factor, interleukin-1 and 11and TGF-b. ${ }^{9}$ Both the cytoprotector, amifostine and the pineal hormone; melatonin have been claimed to have some effects in the prevention of mucositis. It has denoted that the potential mechanism of $\mathrm{c}$ thalidomide action might include inhibition of cytokines such as interleukin-1, interleukin-6 and TNF-a, that are supposed to take part in the pathogenesis of oral mucositis. ${ }^{10}$ Some of the dietary means including

Cite this article: Vyshnavi, Gayathri Rao, Nayak S, Shetty BV. Evaluation of Modulatory Effect of Combination of Spondias Pinnata and Whey Preparation on Intestinal Antioxidants and Inflammatory Markers in Etoposide Induced Rat Model for Mucositis. Pharmacog J. 2018;10(4):640-4. 
both animal and plant products could relieve some of the complications of mucositis. ${ }^{11}$

Spondias pinnata (Anacardiaceae) is a deciduous tree distributed in India, Sri Lanka and South-East Asian countries. The gum exudates of the species have been found to contain acidic polysaccharides. ${ }^{12} \mathrm{~A}$ crude extract of $S$. pinnata has been reported to show antibacterial activity. In ethnomedicine, bark juice of $S$. pinnata is prescribed as a remedy for dysentery. ${ }^{13}$ and is shown to have antioxidant and free radical scavenging activity. ${ }^{14}$ and some anti-mucositic property.

Whey preparation derived from milk, is being touted as a functional food and can act as an antioxidant, antihypertensive, antitumor, hypolipidemic, antiviral, antibacterial and chelating agent. Moreover, the whey preparation is an ethnic dietary component used during diarrhea. Many clinical trials have successfully been performed using whey in the treatment of cancer, HIV, hepatitis B, cardiovascular disease, osteoporosis, and as an antimicrobial agent also. Whey protein has also exhibited benefit in the arena of exercise modulatory effect of SP and WP on rat intestine with mucositis performance and enhancement. ${ }^{15}$ Here we tried to find the effect of such dietary component on mucositis.

\section{MATERIALS AND METHODS}

\section{Experimental design}

Adult albino female rats of Wistar strain were used for the study. Animals weighing about 220-250 g obtained from Central animal house, Kasturba Medical College, Mangalore, India, were the subjects of the study.

Animals were acclimatized for a period of two-weeks and were then treated. They received standard pellet and water ad libitum. Rats were coded in groups of two per cage. Single dose of etoposide (60 mg/kg, i.p) was administered. S. pinnata extract and whey preparation was administered by orogastric gavage to the study group once in a day.

Animal grouping $(\mathrm{n}=6)$

Group 1 Normal control.

Group 2 The rats received Etoposide alone (i.p) in a single dose of $60 \mathrm{mg}$ per kg body weight.

Group 3 The rats received Etoposide (i.p) followed by Spondias pinnata bark extract in a dose of $100 \mathrm{mg}$ per kg body weight, orally once in a day from $0 \mathrm{~h}$. to $72 \mathrm{~h}$.

Group 4 The rats received Etoposide (i.p) followed by whey preparation in a dose of $100 \mathrm{mg}$ per $\mathrm{kg}$ body weight orally once in a day from $0 \mathrm{~h}$. to $72 \mathrm{~h}$.

Group 5 The rats received Etoposide (i.p) followed by a combination of $S$. pinnata and whey preparation in a dose of $100 \mathrm{mg}$ per kg body weight orally once in a day from $0 \mathrm{~h}$ to $72 \mathrm{~h}$.

The change in the body weight and food intake was monitored on daily basis. After $72 \mathrm{~h}$, rats were sacrificed by cervical dislocation. The small intestine was dissected out, washed in ice-cold PBS, and blotted. The middle piece was used for assessment of biochemical parameters. Samples were immediately homogenized and stored at $-20^{\circ} \mathrm{C}$ until analysis.

\section{Chemicals}

Chemicals and reagents were of HPLC or analytical grade procured from Sri Durga Laboratories, Mangalore, India.

\section{Biochemical parameters Estimation of total antioxidants (TAO)}

The total antioxidants level was estimated according to the method described by. ${ }^{16}$ Each sample had its own control in which Fe-EDTA mixture, hydrogen peroxide and sodium benzoate were added after $20 \%$ acetic acid. For each series of analysis, a negative control was prepared, except that sample homogenate was replaced with $0.1 \mathrm{M}$ Sodium phosphate buffer, $\mathrm{pH} 7.4$. Uric acid $(1 \mathrm{Mm} / \mathrm{L})$ was used as standard. The reaction mixture was incubated at $37^{\circ} \mathrm{C}$ for $60 \mathrm{~min}$, then $20 \%$ Acetic acid and $0.8 \%$ TBA were added and incubated for $10 \mathrm{~min}$ at $100^{\circ} \mathrm{C}$, then modulatory effect of SP and WP on rat intestine with mucositis cooled in ice bath. The absorbance was measured at $532 \mathrm{~nm}$. The total antioxidants level is expressed as $\mu \mathrm{mol} / \mathrm{L}$.

\section{Estimation of Reduced Glutathione}

Tissue GSH concentration was estimated according to the method described by Ellman. ${ }^{17}$ One milliliter of supernatant was precipitated with $1 \mathrm{ml}$ of metaphosphoric acid and cold digested at $4^{\circ} \mathrm{C}$ for $1 \mathrm{~h}$. The samples were centrifuged at $1,200 \mathrm{~g}$ for $15 \mathrm{~min}$ at $4^{\circ} \mathrm{C}$. To $1 \mathrm{ml}$ of this supernatant, $2.7 \mathrm{ml}$ of phosphate buffer and $0.2 \mathrm{ml}$ of 5,5 ' dithio-bis-2nitrobenzoic acid (DTNB) were added. The yellow color developed was read immediately at $412 \mathrm{~nm}$ using a Systronic-117 UV-Visible spectrophotometer. The values were expressed in $\mathrm{mg} / \mathrm{gm}$ of wet tissue.

\section{Assay for lipid peroxidation (LPO)}

The lipid peroxidation products in the homogenate were measured through the estimation of Thiobarbituric acid reactive substances (TBARS) by the method described by.$^{18} 1 \mathrm{ml}$ of tissue homogenate was precipitated with $2.5 \mathrm{ml}$ of ice cold Trichloroacetic acid (TCA). The samples were centrifuged at $3000 \mathrm{~g}$ for $10 \mathrm{~min}$.To $2 \mathrm{ml}$ of this supernatant, $0.67 \%$ of Thiobarbituric acid (TBA) was added and kept in boiling water bath for $10 \mathrm{~min}$ and cooled. The pink chromogen that was developed was read immediately at $532 \mathrm{~nm}$.TBARS concentration was calculated using molar extinction co-efficient of chromophore $\left(1.56 \times 10^{5}(\mathrm{~mol} / \mathrm{l})^{-1} \mathrm{~cm}^{-1}\right.$ and the values were expressed in nmloes/L.

\section{Estimation of nitric oxide}

Activity of nitric oxide was determined by the procedure of Green et al. ${ }^{19}$ The accumulation of nitrite in the supernatant is an indicator of production of nitric oxide (NO), which is produced due to oxidative stress occurring in the brain. Production of NO was determined by spectrophotometric assay with Griess reagent $(0.1 \% \mathrm{~N}-1$-Napththyl ethylene diamine dihydrochloride, $1 \%$ sulphanilamide and $2.5 \%$ phosphoric acid). Equal volume of homogenate and Griess reagent was be mixed, the mixture was incubated for $10 \mathrm{~min}$ at room temperature and absorbance was measured at $450 \mathrm{~nm}$. The concentration of nitrite on the supernatant was determined from standard curve and expressed in $\mu \mathrm{g} / \mathrm{g}$.

\section{Myeloperoxidase (MPO)}

Myeloperoxidase activity was measured spectrophotometrically. ${ }^{20}$ by using 4-AAP (4-Amino Antipyrine) as the hydrogen donor. Activity was measured as an increase in absorbance at $510 \mathrm{~nm} / \mathrm{min}$. Test analysis Add 100 microliter homogenate, $0.5 \mathrm{ml}$ buffer, $0.5 \mathrm{ml}$ and $0.5 \mathrm{ml}$ 4-AAP. Immediately after the addition of 4-AAP, read in a spectrophotometer at 1' interval for $5 \mathrm{~min}$. Control analysis-Add 100 microliters homogenates, $1.0 \mathrm{ml}$ buffer, and $0.5 \mathrm{ml}$ 4-AAP. Immediately after the addition of 4-AAP, read in a spectrophotometer at l'interval for $5 \mathrm{~min}$. One unit of myeloperoxidase activity is defined as the amount of enzyme producing 1 nmole of hydrogen peroxide per min. Modulatory effect of SP and WP on rat intestine with mucositis.

\section{RESULTS}

Rats which received etoposide alone (group 2) showed significant decrease $(\mathrm{p}<0.01)$ in the TAO levels compared to control groups (group $1 \mathrm{v} / \mathrm{s}$ group 2). Animals which received etoposide followed by Spondias pinnata $(100 \mathrm{mg} / \mathrm{kg} \mathrm{b} \mathrm{w})$ showed significant increase $(\mathrm{p}<0.01)$ in TAO level when compared to animals exposed to etoposide alone (group $2 \mathrm{v} / \mathrm{s}$ group 5). Animals which received etoposide followed by whey $(100 \mathrm{mg} /$ $\mathrm{kg} \mathrm{bw})$ and combination (100 $\mathrm{mg} / \mathrm{kg} \mathrm{bw})$ showed significant increase 


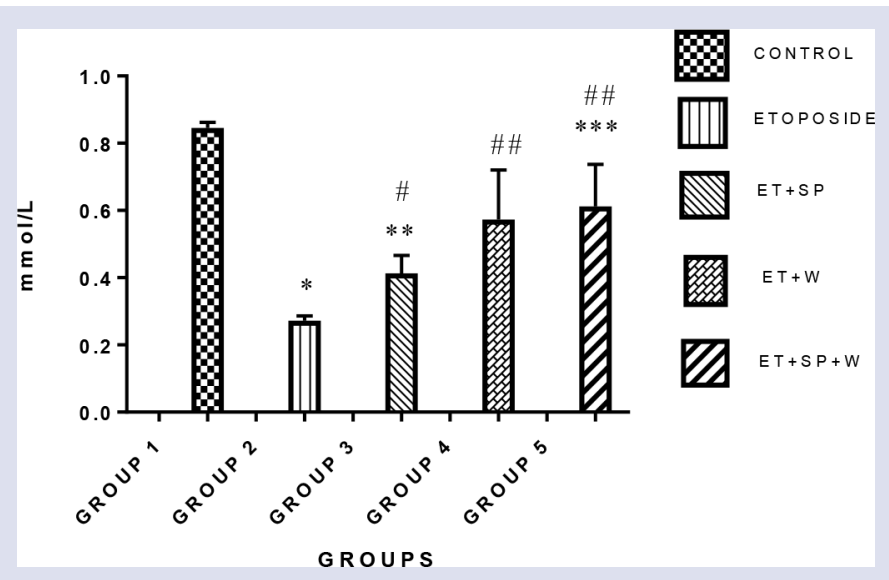

Figure 1: Total Antioxidant level $(\mathrm{mmol} / \mathrm{L})$ in rat duodenal tissue. ANOVA significance (Bonferroni's test, each bar represents Mean \pm SEM, $\mathrm{n}=06$ ).

Group1 vs group 2, group 3 and group $5,{ }^{*} p<0.0001,{ }^{* *} p<0.01,{ }^{* * *} p<0.05$. Group 2 vs group 3, group 4 and group 5, \#p $<0.01$, \#\#p $<0.05$.

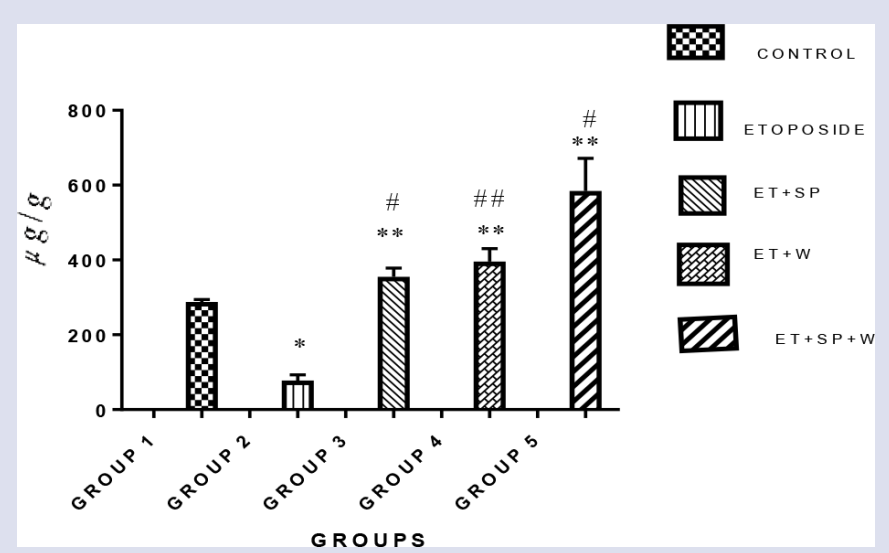

Figure 2: Duodenal GSH level $(\mu \mathrm{g} / \mathrm{g})$ in rats.

ANOVA Significance (Bonferroni's test, each bar represents Mean \pm SEM, $\mathrm{n}=06$ ).

Group 1 vs group 2, group 3, group 4, and group5, ${ }^{*} \mathrm{p}<0.0001,{ }^{* *} \mathrm{p}<0.01$

Group2 vs group 3, group4 and group5, \#p $<0.0001$, \#\#p<0.01.

in TAO level when compared to animals exposed to etoposide alone $\mathrm{p}<0.05$. (Figure 1 )

Rats which received etoposide alone (group 2) showed a significant decrease $(p<0.0001)$ in GSH levels compared to controls (group $1 \mathrm{v} / \mathrm{s}$ group 2). Animals which received etoposide followed by Spondias pinnata $(100 \mathrm{mg} / \mathrm{kg} \mathrm{bw})$, whey $(100 \mathrm{mg} / \mathrm{kg} \mathrm{bw})$ and combination showed significant increase $(\mathrm{p}<0.01)$ in GSH levels when compared to animals exposed to etoposide alone (group $2 \mathrm{v} / \mathrm{s}$ group 5). (Figure 2)

Animals exposed to chemotherapy showed significant increase in the TBARS level in duodenum compared to controls $(\mathrm{p}<0.0001)$. Animals exposed to chemotherapy followed by $S$ pinnata bark extract and combination showed significant decrease in TBARS level compared to etoposide control. (Etoposide vs $S$ pinnata and combination, $\mathrm{p}<0.0001$ ) and there a decrease in TBARS levels in animals exposed to chemotherapy followed whey proteins $(\mathrm{p}<0.001)$. (Figure 3 )

A significant increase in duodenal $\mathrm{NO}$ level was observed in rats exposed to etoposide compared with control group $(\mathrm{p}<0.01)$. Animals which

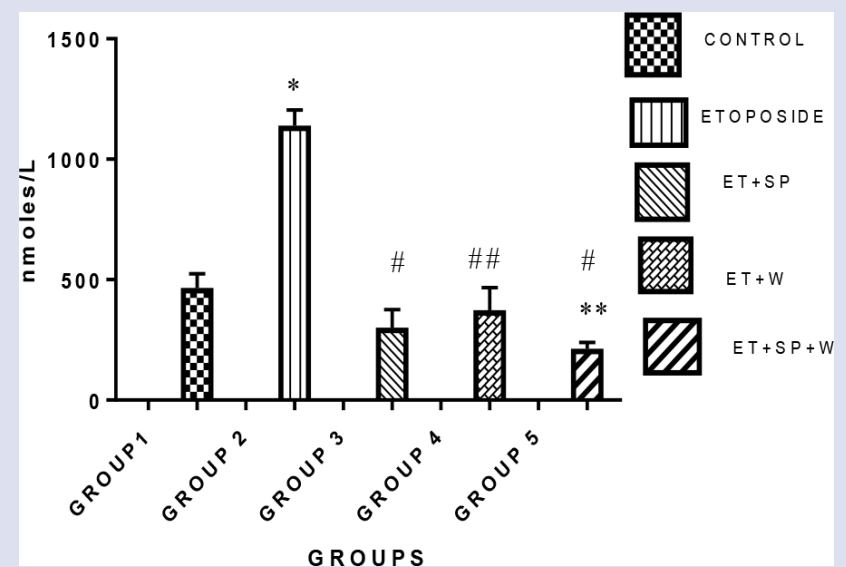

Figure 3: Estimation of TBARS level ( $n$ moles/L) in rat duodenum. ANOVA Significance (Bonferroni's test, each bar represents Mean \pm SEM, $\mathrm{n}=06$ ).

Group 1 vs group 2 and group $5,{ }^{*} p<0.0001,{ }^{* *} p<0.001$.

Group 2 vs group 3, group 4, and group 5, \#p $<0.0001$, \#\#p $<0.001$

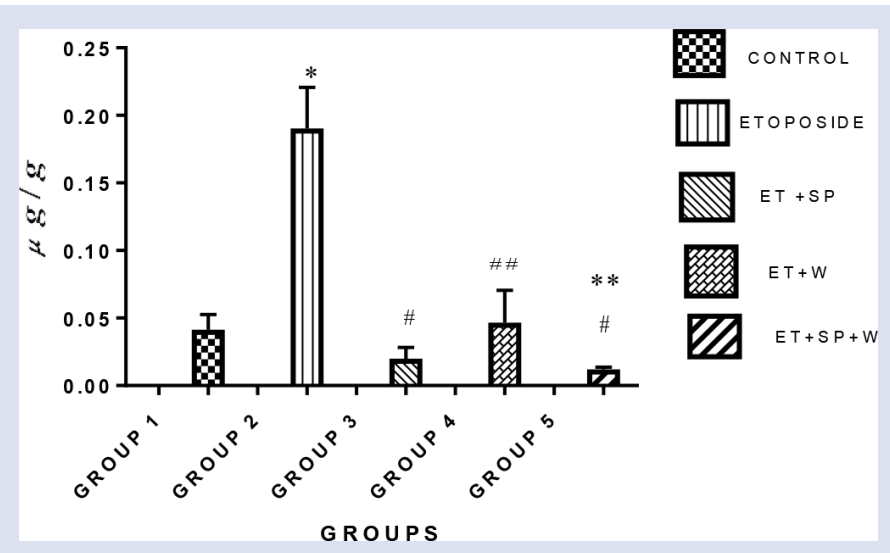

Figure 4: Duodenal Nitric Oxide level ( $\mu \mathrm{g} / \mathrm{g}$ of tissue) in rats. ANOVA Significance (Bonferroni's test, each bar represents Mean \pm SEM, $\mathrm{n}=06$ ).

Group 1 vs group2 and group $5,{ }^{*} p<0.01,{ }^{* *} p<0.05$

Group2 vs group 3, group 4 and group 5, \#p<0.001, \#\#p $<0.01$.

received etoposide followed by S. pinnata (100 mg / kg body weight) and combination ( $100 \mathrm{mg} / \mathrm{kg}$ body weight) treatment showed a

\section{Modulatory effect of SP and WP on rat intestine with mucositis}

significant decrease in duodenal nitric oxide level ( $p<0.001)$, when compared to rats which received etoposide alone (group $2 \mathrm{v} / \mathrm{s}$ group 5 ) and in rats which received whey $100 \mathrm{mg} / \mathrm{kg}$ body weight. (Figure 4)

The MPO activity was significantly increased $(\mathrm{p}<0.0001)$ in animals exposed to etoposide alone compared to control group. Animals exposed to etoposide followed by.$S$ pinnata $(100 \mathrm{mg} / \mathrm{kg}$ bw), whey $(100 \mathrm{mg} / \mathrm{kg}$ bw) and combination showed significant decrease in MPO level in the duodenum compared to etoposide controls $(\mathrm{p}<0.0001)$. (Figure 5)

\section{DISCUSSION}

Mucositis is a foremost cause of dosage reduction and untimely interruption of treatment during cancer therapy, and thus significantly influences the survival of cancer patients. Patients with mucositis leads to severe 


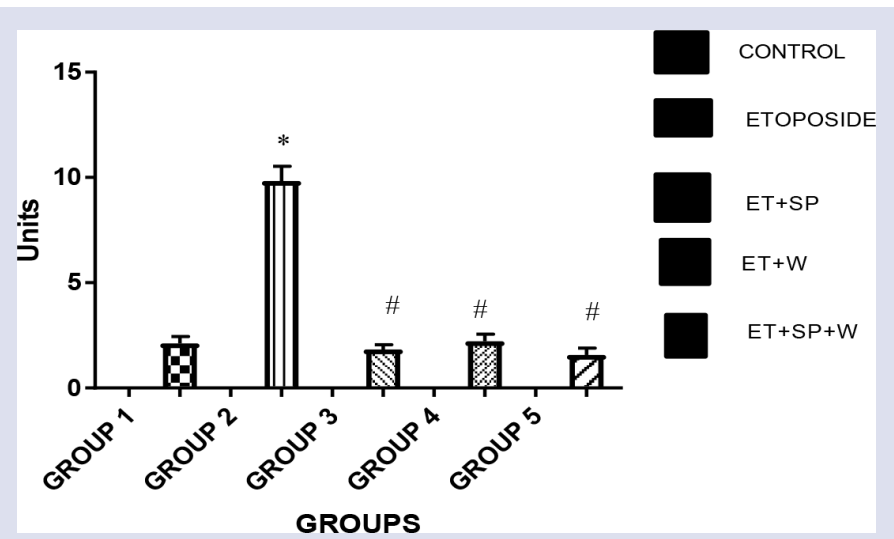

Figure 5: Estimation of MPO activity in Rats.

ANOVA Significance (Bonferroni's test, each bar represents Mean \pm SEM, $\mathrm{n}=06$ ).

Group1 vs group 2, ${ }^{*} \mathrm{p}<0.0001$.

Group 2 vs group 3, Group 4 and group 5, \#p $<0.0001$.

clinical symptoms, including pain resulting from ulceration, nausea, vomiting, heartburn, diarrhea, constipation, succeeding malnutrition and weight loss. ${ }^{1,21}$ Ulceration is concomitant with a threat of systemic infection. Therefore, mucositis is a major clinical and economic cargo that severely affects patient outcome and quality of life, in addition to increasing the risk of morbidity and mortality. ${ }^{22}$ However, currently the all available means of management of mucositis are largely limited to the control of its pain, oral hygiene, infection, bleeding, and malnutrition., ${ }^{8,14}$ but with some major side effects. Current study is planned to implicate some commonly used dietary means to check their impact on mucositis. The side- effects may also result in termination of therapy and hence there is a requirement for better and alternate adjuvant therapy. Literature survey shows that $S$ pinnata bark extract contains large amounts of flavanoids, and phenolic compounds which exhibit high antioxidant and free radical scavenging activities. ${ }^{23}$

Rats which received etoposide alone showed significant decrease in the TAO levels compared to control groups. Administration of whey preparation and combination following etoposide treatment have shown more significant increase in the TAO levels than treatment with S. pinnata. The cationic whey protein isolate has been shown to have antioxidant effect in model experimental systems, and so can be considered as a factor that can regulate the intensity of lipid oxidation. ${ }^{24} \mathrm{GSH}$ is a major component of the intestinal antioxidant system. Several studies have confirmed the role of glutathione, as a powerful antioxidant, which is increased by dietary whey protein. ${ }^{25,26}$ Moreover, whey proteins are a source of cysteine, a precursor for the synthesis of gluthatione (GSH) that plays a key role in endogenous cellular antioxidant defences. ${ }^{27}$ Whey preparation has been found to restore Glutathione levels in leukocytes, liver and cutaneous tissue in mice by suppressing hydroperoxide and ROS levels. ${ }^{28}$ Accumulation of GSSG by oxidative mechanisms within the cytosol may lead to cell apoptosis. S. pinnata intervention brings about the restoration of GSH levels in kidney and liver tissue. Increased free radical stress disturbs the membrane lipids by their oxidation, results in the formation of products such as malondialdehyde and TBARS and will worsen normal functioning of the cells. ${ }^{29}$ Beta sitosterol present in S. pinnata has been implicated in protecting glutathione by decreasing levels of cytokines. ${ }^{23}$ The study showed significant decrease in GSH levels in rats exposed to chemotherapy compared to normal controls. Administration of Spondias pinnata $(100 \mathrm{mg} / \mathrm{kg}$ b.w) or whey preparation (100

\section{Modulatory effect of SP and WP on rat intestine with mucositis}

$\mathrm{mg} / \mathrm{kg} \mathrm{b.w)} \mathrm{following} \mathrm{etoposide} \mathrm{treatment} \mathrm{showed} \mathrm{increase} \mathrm{in} \mathrm{the} \mathrm{GSH}$ levels. However, the increase in GSH levels after the administration of combination of Spondias pinnata and whey preparation (100 mg each/ $\mathrm{kg} \mathrm{b.w)} \mathrm{following} \mathrm{etoposide} \mathrm{is} \mathrm{much} \mathrm{more} \mathrm{than} \mathrm{either} \mathrm{administered} \mathrm{indi-}$ vidually, showing that the compounds present in them act synergistically in increasing GSH levels.

The level of Thiobarbituric acid reactive substances (TBARS) is a scale of lipid peroxidation. Augmented free radical stress disturbs the membrane lipids by their oxidation which results in the formation of products such as malondialdehyde and TBARS and will exacerbate normal functioning of the cells. ${ }^{30}$ Animals exposed to chemotherapy showed significant increase in TBARS level in the duodenum compared to control group. Animals exposed to chemotherapy followed by Spondias pinnata bark extract or whey preparation or combination showed a significant decrease in TBARS level in duodenum equated to etoposide control.

Nitric oxide (NO) is known as an endothelium derived relaxing factor. ${ }^{31}$ There are some evidences that injuries of the small intestine may be exacerbated significantly by elevated NO levels. ${ }^{32}$ Present study showed significant increase in nitric oxide levels in etoposide treated group compared to control. Administration of a combination of Spondias pinnata extract and Whey preparation showed a more significant reduction in the NO levels than with either Spondias pinnata extract or Whey preparation alone. 4-O- $\beta$-glucoside, a component of $S$. pinnata extract has been shown to inhibit nitric oxide synthase, thus decreasing nitric oxide levels. ${ }^{33,34}$ Whey protein and $\alpha$-Lactalbumin may decrease nitric oxide production by inhibiting the production of mediating cytokines. ${ }^{35}$ MPO is an inflammatory marker and is found to intensify during tissue injury. An elevation in MPO activity was observed after etoposide treatment, which indicates the acculamation of neutrophils that might contribute to etoposide induced small intestinal damage. ${ }^{36}$ The levels of MPO in current study is significantly increased in rats that received etoposide alone when compared to normal control may be due to increased levels of free radicals generated during the development of mucositis. There was significant decrease in the level of MPO in the rats which received etoposide followed by Spondias pinnata, whey preparation and the combination. The complications of mucositis could be inhibited by modulating the underlying pathways provides an opportunity for the development of more targeted therapies and interventions. Thus the development of an effective intervention against chemotherapy related mucositis has high priority in oncological supportive care.

\section{CONCLUSION}

The study results demonstrates that combination of S.pinnata with whey preparation have better effect on the prevention/ recovery from mucositis.

\section{ACKNOWLEDGEMENT}

No acknowledgements- since there is no findings.

\section{CONFLICT OF INTEREST}

The authors declare no conflict of interest.

\section{ABBREVIATIONS}

GSH: Reduced Glutathione; TAO: Total Anti-Oxidants; MPO: MyeloPeroxidase; SP: Spondias Pinnata; WP: Whey Preparation.

\section{REFERENCES}

1. Bellm LA, Epstein JB, Rose-P A, Martin P, Fuchs HJ. Patient reports of complications of bone marrow transplantation. Support Care Cancer. 2000;8(1):33-9.

2. Blijlevens NM, Donnelly JP, De Pauw BE. Mucosal barrier injury:biology, pathology, 
clinical counterparts and consequences of intensivetreatment for haematological malignancy: an overview. Bone Marrow Transplant. 2000;25(12):1269-78.

3. Sonis ST. The pathobiology of mucositis. Nat Rev Cancer. 2004;4(4):277-84.

4. Shetty B, Rao G, Abhineetha, Banu N, Preethika and Sudarshan Reddy. Study of Protective Action of Spondias pinnata Bark extract on Rat Liver and Kidney against Etoposide Induced Chemical Stress. Pharmacognosy Journal. 2016;8(1):24-27.

5. Parkhill A. Oral mucositis and stomatitis associated with conventional and targeted anticancer therapy. J Pharmacovigil. 2013;1(4):1000-12.

6. Tran CD, Sundar S, Howarth GS. Dietary zinc supplementation and methotrexate-induced small intestinal mucositis in metallothionein-knockout and wild-type mice. Cancer Biol Ther. 2009;8(17):1662-7.

7. Whitford EJ, Cummins AG, Butler RN, Prisciandaro LD, Fauser JK, Yazbeck R, et al. Effects of streptococcus thermophilus th-4 on intestinal mucositis induced by the chemotherapeutic agent, 5-fluorouracil (5-fu). CancerBiol Ther. 2009;8(6):505-11.

8. Wright TH, Yazbeck R, Lymn KA. The herbal extract, iberogast, improves jejuna integrity in rats with 5-fluorouracil (5-fu)-induced mucositis. Cancer Biol Ther. 2009;8(10):923-9

9. Susan H, Santosh R, Matthew Z k, Nijole B, Devinder A ,Catherine M M et al. Protection against Radiotherapy-Induced Toxicity. Antioxidants. 2016;5(3):22

10. Owlia F, kazem Kazemeini S, Gholami N. Prevention and Management of Mucositis in Patients with Cancer: a Review Article. Iran J Can Prevention. 2012;5(4):216-20.

11. Glasauer A, Chandel NS. Targeting antioxidants for cancer therapy. Biochem Pharmacol. 2014;92(1):90-101.

12. Bibitha B, Jisha VK, Salitha CV, Mohan S, Valsa AK. Antibacterial activity of different plant extracts. Indian J Microbiol. 2002;42(4) 361-63.

13. Mahanta RK, Rout SD, Sahu HK. Ethnomedicinal plant resources of Similipal biosphere reserve, Orissa, India. Zoos Print. 2006;21(8):2372-4.

14. Bibhabasu H, Santanu B, Nripendranath M. Antioxidant and free radical scavenging activity of Spondias pinnata. BMC Complementary and Alternative Medicine. 2008;8(1):63.

15. Robert Silverman. The Whey to Go for Athletes. Altern MedRev. 2004;9(2):138-56

16. Koracevic D, Koracevic G, Djordjevic V, Andrejevic S, Cosic V. Method for the measurement of antioxidant activity in human fluids. J Clin Pathol 2001:54(5):356-61

17. Ellman GL. Tissue sulfhydryl groups. Arch Biochem Biophys. 1959;82(1):70-7.

18. Rao GM, Rao AV, Raja A, Rao S, Rao A. Lipid peroxidation in brain tumours. Clinica Chimica Acta; International Journal of Clinical Chemistry. 2000;302(1):205-11.

19. Green LC, Wagner DA, Glogowski J, Skipper PL, Wishnok, JS, Tannenbaum SR. Analysis of nitrate, nitrite, and [ 15N]nitrate in biological samples. Anal.
Biochem. 1982;126(1):131- 8.

20. Kettle AJ, Winterbourn CC. "Assays for the Chlorination Activity of Myeloperoxidase". Methods in Enzymology. 1994;33:502-12.

21. Youngjoo K. Mechanism-based management for mucositis: option for treating side effects without compromising the efficacy of cancer therapy. Onco Targets The. 2016;9:2007-16.

22. Vivancos M, Moreno J. Beta sitosterol modulates antioxidant enzyme response in RAW macrophages. Free Radical Biology and Medicine. 2005;39(1):91-7.

23. Bibhanshu $H$, Santanu B, Nripendranath M. Antioxidant and free radical scavenging activity of Spondias pinnata. BMC Complement Altern Med. 2008;8(1):63.

24. Titova ME, Komolov SA, Tikhomirova NA, Vopr Pitan. Antioxidant activity of cationic whey protein isolate. 2012;81(6):37-40.

25. Bounous G. Whey protein concentrate (WPC) and glutathione modulation in cancer treatment. Anticancer Research. 2000;20(6):4785-92.

26. Lands L, Grey V, Smountas A. Effect of supplementation with a cysteine donor on muscular performance. Journal of Applied Physiology. 1999;87(4):1381-5.

27. Meister A. Glutathione, ascorbate, and cellular protection. Cancer Res. 1994;54(7):1969-75s.

28. Ebaid H, Badr G, Metwalli A. Immunoenhancing propert of dietary un-denatured whey protein derived from three camel breeds in mice. Biologia. 2012;67(2):425-33.

29. Morrow PK, Tarrand JJ, Taylor SH, Sau SW, Theriault RL, Hortobagyi GN, et al. Effects of chronic hepatitis $\mathrm{C}$ infection on the treatment of breast cancer patients. Ann Oncol. 2009;21(6):1233-6.

30. Palmer RM, Ferrige A, Moncada S. Nitric oxide release accounts for the biological activity of endothelium-derived relaxing factor. Nature. 1987;327(6122):524-6.

31. Pedoto A, Nandi J, Oler A, Camporesi EM, Hakim TS, Levine RA. Role of nitric oxide in acidosis-induced intestinal injury in anaesthetized rats. JI of Lab and Clin Med. 2001;138(4):270-6.

32. Tandon S, Rastogi R. Studies on the chemical constituents of Spondias pinnata. Planta Medica. 1976;29(2):190-2.

33. Park H J, Jumg W T, Basnet $P$, Kadota S, Namba T. Syrigin 4-O- $\beta$-glucoside, a new phenylproponide glycoside, and costunolide, a nitric oxide synthase inhibitor, from the stem bark of magnolia seiboldii. J of Natural Products. 1996;59(12):1128-30.

34. Yamagichi M, Uchida M. $\alpha$-Lactalbumin suppresses interleukin-6 release after internal ischemia/reperfusion via nitric oxide in rats. Inflammopharmacology. 2007; 15(1):43-7.

35. Patel S. Emerging trends in nutraceutical applications of whey protein and its derivatives. J Food Sci Technol. 2015;52(11):6847-58

36. Sahu S, Madhyastha S, Rao G. Effect of Prenatal Stress on Expression of Glutathione System in Neonatal Rat Brain. Turkish Neurosurgery. 2012;22(5):576-82.

\section{GRAPHICAL ABSTRACT}

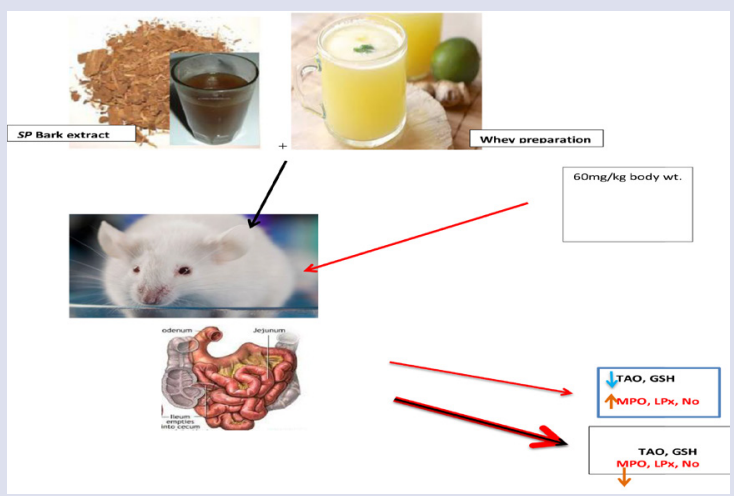

\section{SUMMARY}

- The study results showed that the antioxidant (TAO and GSH) were found to be significantly high in the rats which received the combination compared to the individual Spondias pinnata and whey treated groups with a significant decrease in the TBARS, NO and MPO levels. Hence it can be considered as anti-mucositis therapeutic agents which can be safely administered during chemotherapy and can reverse mucositis Spondias pinnata and whey preparation supplementation in combination have shown mucoprotective effects in rat model.

\section{ABOUT AUTHORS}

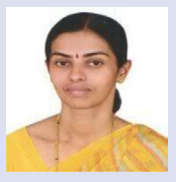

Gayathri Rao: Is Associate Professor in Biochemistry, at Kasturba Medical college mangaluru, Manipal University. She has obtained her Ph.D degree in 1999 from Manipal Academy of Higher Education, Manipal. Currently her research focused on evaluation of therapeutic and preventive solutions from natural products against cancer and mucositis.

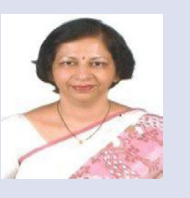

Beena Shetty: Obtained her Ph.D degree from Kasturba medical college, Manipal,Mysore university Mysore in 1987. Currently, sheisProfessor of Biochemistry, at Kasturba Medical college, Mangaluru, Manipal Academy of Higher Education,Manipal

Cite this article: Vyshnavi, Gayathri Rao, Nayak S, Shetty BV. Evaluation of Modulatory Effect of Combination of Spondias Pinnata and Whey Preparation on Intestinal Antioxidants and Inflammatory Markers in Etoposide Induced Rat Model for Mucositis. Pharmacog J. 2018;10(4):640-4. 